Article

\title{
The Protective Role of Hydrogen Sulfide Against Obesity-Associated Cellular Stress in Blood Glucose Regulation
}

\author{
Ania Mezouari ${ }^{\circ}$, Radhika Nangia and Jeffrey Gagnon* \\ Department of Biology, Laurentian University, Sudbury, ON P3E 2C6, Canada; amezouari@laurentian.ca (A.M.); \\ rnangia23@gmail.com (R.N.) \\ * Correspondence: jdgagnon@laurentian.ca
}

Received: 11 September 2020; Accepted: 20 October 2020; Published: 23 October 2020

check for updates

\begin{abstract}
Circulating palmitic acid (PA) is increased in obesity and causes metabolic stress, leading to diabetes. This includes the impairment of the glucoregulatory hormone glucagon-like peptide-1 (GLP-1) secreted from intestinal L-cells. Recently, the anti-inflammatory gasotransmitter hydrogen sulfide $\left(\mathrm{H}_{2} \mathrm{~S}\right)$ has been implicated in the enhancement of GLP-1 secretion. We hypothesized that $\mathrm{H}_{2} \mathrm{~S}$ can reduce the oxidative stress caused by palmitate and play a protective role in L-cell function. This study was conducted on both human and mouse L-cells and a mouse model of Western diet (WD)-induced obesity. PA-induced L-cell stress was assessed using DCF-DA. $\mathrm{H}_{2} \mathrm{~S}$ was delivered using the donor GYY4137. C57BL/6 mice were fed either chow diet or PA-enriched WD for 20 weeks with ongoing measurements of glycemia and GLP-1 secretion. In both L-cell models, we demonstrated that PA caused an increase in reactive oxygen species (ROS). This ROS induction was partially blocked by the $\mathrm{H}_{2} \mathrm{~S}$ administration. In mice, the WD elevated body weight in both sexes and elevated fasting blood glucose and lipid peroxidation in males. Additionally, a single GYY4137 injection improved oral glucose tolerance in WD-fed male mice and also enhanced glucose-stimulated GLP-1 release. To conclude, $\mathrm{H}_{2} \mathrm{~S}$ reduces oxidative stress in GLP-1 cells and can improve glucose clearance in mice.
\end{abstract}

Keywords: hydrogen sulfide; antioxidant; glucoregulation; GLP-1

\section{Introduction}

Obesity has reached epidemic proportions worldwide with a prevalence that has tripled since 2016, and a projection that nearly half of the US population will be obese by 2030, as reported by the World Health Organization. Obesity is a disease defined based on the calculation of the body mass index (BMI) being higher than $30 \mathrm{~kg} / \mathrm{m}^{2}$ and, more specifically, with an abnormal fat depot. Excessive body fat accumulation in adipocytes is an established cause of metabolic impairment [1] and is closely linked with complications such as heart disease, stroke, and type 2 diabetes mellitus [2].

Medications that successfully combat obesity are limited. One group of anti-obesity treatments that are being used are the Glucagon-like peptide-1 (GLP-1) drugs [3]. These either prolong the half-life of endogenous GLP-1 such as dipeptidyl peptidase-4 (DPP4) inhibitors, or act as GLP-1 receptor agonists. The latter successfully target obesity (1-3 kg after 26/30 weeks), whereas Dipeptidyl peptidase-4 inhibitors are weight-neutral [4,5]. GLP-1 increases insulin release, enhances insulin action, acts as a satiety signal, and slows gastric emptying, leading to reduced food intake and weight loss [6]. Normally, GLP-1 is secreted by endocrine L-cell found in the colon and the ileum in response to food consumption [7,8]. Unfortunately, GLP-1 secretion may be impaired in obese individuals, and this may contribute to the hyperglycemia and decreased satiety seen during obesity [9]. The mechanism leading to obesity-induced GLP-1 impairment is not clearly known. 
As fat accumulation correlates with systemic oxidative stress [10], and this can lead to impaired function of cells $[11,12]$, these effects may explain the impaired GLP-1 secretion seen during obesity. In particular, elevated palmitic acid (PA, 16:0) has been implicated in metabolic stress through increases in oxidative stress and elevation of cellular reactive oxygen species (ROS) [13]. Elevated ROS will contribute to cellular dysfunction if not balanced by antioxidants.

Hydrogen sulfide $\left(\mathrm{H}_{2} \mathrm{~S}\right)$ is a gasotransmitter that acts as a signaling molecule and as an antioxidant [14]. It is produced endogenously from L-cysteine by the enzymes cystathionine gammalyase and cystathionine beta-synthase [15], and by the gut microbiome by a variety of sulfate-reducing bacteria (SRB) [16]. Importantly, these SRB are localized in the distal ileum and colon, which is the same niche as GLP-1 secreting L-cells [7]. Recently, we demonstrated a role for bacterial $\mathrm{H}_{2} \mathrm{~S}$ in the stimulation of GLP-1 secretion [17]. However, the precise mechanism of how this occurs and whether $\mathrm{H}_{2} \mathrm{~S}$ can protect from obesity-induced metabolic stress is not known. As a follow up to this work, we set out to examine the role of $\mathrm{H}_{2} \mathrm{~S}$ as a protective antioxidant under palmitate-induced metabolic stress. This was examined in GLP-1 secreting L-cells and obese mice.

\section{Materials and Methods}

\subsection{Cell Culture}

The human NCI-H716 cell line was obtained from American Type Culture Collection (ATCC). The mouse GLUTag cell line was obtained from Dr. D. Drucker (Lunenfeld-Tanenbaum Research Institute, Toronto, ON, Canada). Cell lines were maintained in $10 \mathrm{~cm}$ plates containing Roswell Park Memorial Institute (RPMI 1640, GE Healthcare Life Sciences, South Logan, UT, USA) medium for the NCI-H716 cells and low-glucose Dulbecco's Modified Eagle's Medium (DMEM, Sigma Aldrich, Oakville, ON, Canada) for GLUTag. Both mediums were supplemented with 1\% penicillin-streptomycin (Pen Strep; Life Technologies, South Logan, UT, USA), and 10\% fetal bovine serum (FBS) (Life Technologies, Waltham, MA, USA) and incubated at $37{ }^{\circ} \mathrm{C}$ in $5 \% \mathrm{CO}_{2}$. Experiments were performed on twenty-four-well plates, which were seeded with cells at a density of 200,000 cells per well for NCI-H716 cells and 250,000 cells per well for GLUTag cells and allowed to proliferate for $48 \mathrm{~h}$. Matrigel (Corning Life Sciences, Bedford, MA, USA) was used to secure the NCI-H716 cells to a basement membrane matrix [18].

\subsection{PA/FAF-BSA Conjugation Preparation}

This study uses the fatty acid preparation method of Cousin [19]. Stock $5 \mathrm{mM}$ PA/fatty acid-free bovine serum albumin (FAF-BSA) was prepared as follows. $100 \mathrm{mM} \mathrm{PA}$ (Sigma Aldrich, Saint Louis, MO, USA) stock solution was dissolved in $0.1 \mathrm{M} \mathrm{NaOH}$ and heated at $70^{\circ} \mathrm{C}$ in a water bath. Simultaneously, a $10 \%(\mathrm{wt} / \mathrm{vol})$ fatty acid-free FAF-BSA (EMD Millipore Corp, Billerica, MA, USA) solution was prepared in deionized $\mathrm{H}_{2} \mathrm{O}$ in a $55^{\circ} \mathrm{C}$ water bath. To prepare a $5 \mathrm{mM} \mathrm{PA} / 10 \%$ FAF-BSA stock solution, $0.5 \mathrm{~mL}$ of the $100 \mathrm{mM}$ PA was added to $9.5 \mathrm{~mL} 10 \%$ BSA solution, which was then heated at $55^{\circ} \mathrm{C}$ in a shaking water bath for $10 \mathrm{~min}$ before it was vortex-mixed for $10 \mathrm{~s}$ and then incubated for an additional $10 \mathrm{~min}$ in a $55^{\circ} \mathrm{C}$ water bath. The PA/FAF-BSA complex solution was cooled to room temperature before being sterile filtered using a $0.45 \mu \mathrm{m}$ pore size filter. Control for this complex was prepared the same way by using just regular BSA (GE Healthcare Life Sciences, GE Healthcare Life Sciences, South Logan, UT, U.S.A). The prepared $5 \mathrm{mM}$ PA/FAF-BSA and regular BSA aliquoted solutions were stored at $-20^{\circ} \mathrm{C}$, where they were stable for three weeks. The stored PA/FAF-BSA and its control stock solutions were heated for $15 \mathrm{~min}$ at $55^{\circ} \mathrm{C}$ and cooled to room temperature before the study.

\subsection{Intracellular ROS Detection}

Levels of intracellular ROS were measured using the cell-permeable dye, 2', 7 -Dichlorofluorescein diacetate (DCF-DA, Sigma-Aldrich, Oakville, ON, Canada). DCF-DA is oxidized in the presence of ROS to produce Dichlorofluorescin (DCF), which is a highly fluorescent compound. After $48 \mathrm{~h}$, the cells 
were washed with phenol red free Hank's Balanced Salt Solution (HBSS, Sigma-Aldrich, Oakville, ON, Canada) and incubated in $1 \mathrm{~mL}$ of HBSS (1x) with $100 \mu \mathrm{M}$ DCF-DA for $10 \mathrm{~min}$ and 30 min for the NCI-H716 and GLUTag cells, respectively. As DCF-DA is sensitive to light and air, the plates were covered with aluminum foil at all times.

The stock $5 \mathrm{mM}$ PA/FAF-BSA was diluted in HBSS to make various treatment concentrations. Regular BSA stock solutions were added to HBSS to match PA concentrations for control. After the 10-min or 30-min dye incubation, the cells were washed with HBSS, and the treatments and controls were added. The cells were then returned to the incubator. Fluorescence was measured using the Fluostar Optima plate reader (BMG Labtech, Offenburg, Germany) at 15 min then at 30-min intervals for two hours. These readings were measured with the excitation filter set to $485 \mathrm{~nm}$ and emission filter at $520 \mathrm{~nm}$.

\subsection{Cytotoxicity Assessment of Palmitate}

To check for the cytotoxic effects of PA, a Neutral Red assay was conducted using the protocol outlined by Repetto [20] with slight modifications. $0.020 \mathrm{~mL}$ of Neutral Red dye (Sigma-Aldrich, Oakville, ON, Canada) was diluted in $5 \mathrm{~mL}$ of each treatment before $1 \mathrm{~mL}$ of the treatment was added to each well. The cells were then returned to the incubator. After $2 \mathrm{~h}$, treatments and dye were aspirated before cells were washed with a wash fixative, composed of distilled water with $1 \%$ calcium chloride and $0.37 \%$ (vol/vol) formaldehyde (Sigma-Aldrich, Oakville, ON, Canada). An extraction solution composed of distilled water with $50 \%$ (vol/vol) bonded ethanol and glacial acetic acid $1 \%$ (vol/vol) (Sigma-Aldrich, Oakville, ON, Canada) was then added. Cells were gently agitated on a Brunswick TM Innova ®2100 Platform Shaker (Eppendorf Canada, Mississauga, ON, Canada) for 5 min to allow for the complete extraction of cells. Readings were measured with absorbance set to $600 \mathrm{~nm}$.

\subsection{Animals}

5 or 6 weeks old C57BL/6 mice of both sexes were purchased from Charles River Laboratories (St. Constant, Quebec) and kept in the Paul Field Animal Care Facility at Laurentian University. Animals were housed in groups on standard 12:12-h light:dark cycles. The Laurentian University Animal Care Committee approved protocols following guidelines of the Canadian Council for Animal Care (CCAC, Ottawa, ON: Vol. 1, 2nd edition, 1993: Vol. 2, 1984).

\subsection{In Vivo Experimental Design}

Upon arrival in the facility, 15 female and 15 male mice were randomly divided into two groups according to diets. Mice had access to water and food ad libitum and were either fed a Western diet $(\mathrm{n}=11$ ) (Research Diets, Inc. New Brunswick, NJ, USA, 43\% Carbohydrates, 40\% fats: 31.32\% PA, $17 \%$ proteins and $14.5 \%$ salt (energy percent)) or a chow diet $(n=4)$ (Envigo Teklad, Madison WI, 40\% Carbohydrates, 5.5\% fats: $0.7 \%$ PA, 22\% proteins and $0.4 \%$ salt (energy percent)) ad libitum for 20 weeks. Blood was collected every two weeks after an oral glucose gavage (OGTT) for glucose and GLP-1 measurements.

\subsection{Oral Glucose Tolerance Test and GLP-1 Determination}

An oral glucose tolerance test (OGTT) was conducted at week 16 of the study. Mice were first injected intraperitoneally with $30 \mathrm{mg} / \mathrm{kg}$ GYY4137 or a vehicle then immediately were fasted overnight for $16 \mathrm{~h}$ before receiving oral gavage of $\mathrm{D}-(+)$-glucose $(2 \mathrm{~g} / \mathrm{kg}$ body $\mathrm{wt})$. Blood glucose was measured from the lateral saphenous vein during the experiment using a glucometer (OneTouch Verio) at 0, 5, 30, 60 , and 90 min after glucose administration. For GLP-1 measurement, blood was collected from the lateral saphenous vein into EDTA coated capillary tubes (Sarsdedt) at 0, 5, and 30 min after glucose gavage. Diprotin A (DPP-4 inhibitor) and aprotinin (a protease inhibitor) were added to the capillary tubes $(10 \% v / v)$ to prevent degradation of the target hormone. The capillary tubes were centrifuged 
at $5000 \times \mathrm{g}$ for $5 \mathrm{~min}$ at $4{ }^{\circ} \mathrm{C}$. $10 \mu \mathrm{L}$ of plasma was examined for total GLP-1 using a commercial competitive ELISA kit (Millipore).

\subsection{In Vivo Oxidative Stress Analysis}

Levels of circulating lipid peroxidation were examined to assess oxidative stress in the Western diet and chow diet mice plasma $(20 \mu \mathrm{L})$ of both sexes. The end product during lipid peroxidation, malondialdehyde (MDA), was measured in blood plasma in a 96-well plate with a colorimetric assay kit (Abcam, Cambridge, MA, USA). Plasma MDA reacts with thiobarbituric acid (TBA), producing the MDA-TBA complex that is quantified at $532 \mathrm{~nm}$ using a microplate absorbance reader.

\subsection{Statistical Analysis}

All values were presented as mean \pm standard error of mean. A one-way ANOVA test analyzed data with multiple doses, followed by a Bonferroni post hoc test. A two-way ANOVA test analyzed data with two or more independent variables, followed by Bonferroni post hoc test at each time point. A Student's $t$-test was used to analyze experiments comparing two groups. Statistical significance was considered at $p<0.05$.

\section{Results}

\subsection{Palmitate Stimulates ROS Production in Both NCI-H716 and GLUTag Cells}

First, we developed a protocol for ROS detection and examined the effect of PA on ROS production in NCI-H716 and GLUTag cell lines. In NCI-H716 cells, PA increased ROS in a time and dose-dependent manner. The $500 \mu \mathrm{M}$ PA, relative to its control, caused the most significant stimulation of ROS by threefold at $120 \mathrm{~min}$ (3.655 \pm 0.186 -fold of control, $p<0.0001$, Figure 1a). In the GLUTag cell line, all the doses tested showed significant stimulation of ROS compared to the corresponding BSA controls by at least one-fold at $120 \mathrm{~min}(2.074 \pm 0.183$-fold of control, $p<0.000$, Figure $1 \mathrm{~b})$. To determine cytotoxicity when cells were treated with treatments of PA, cells was assessed via neutral red assay. Relative to BSA controls, the $500 \mu \mathrm{M}$ of palmitate was not toxic to NCI-H716 (Figure 1c). However, a modest but significant effect was observed in GLUTag cells $(0.915 \pm 0.090$-fold of control, $p<0.05$, Figure 1d).

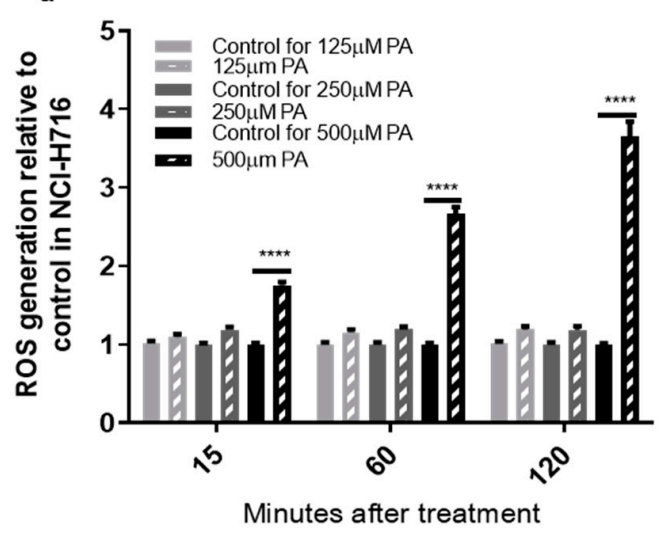

b

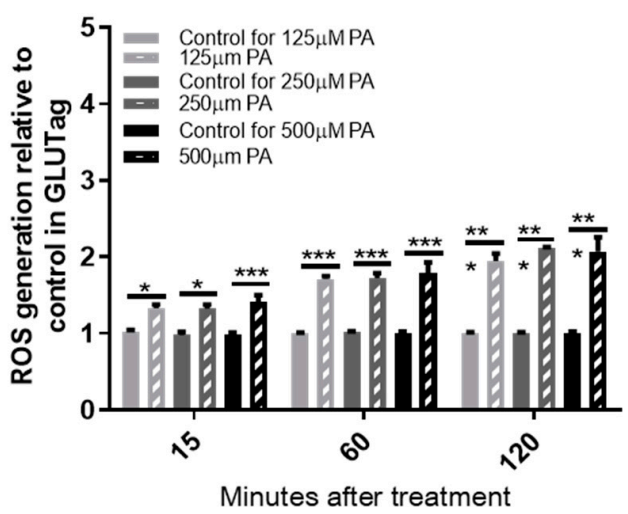

Figure 1. Cont. 


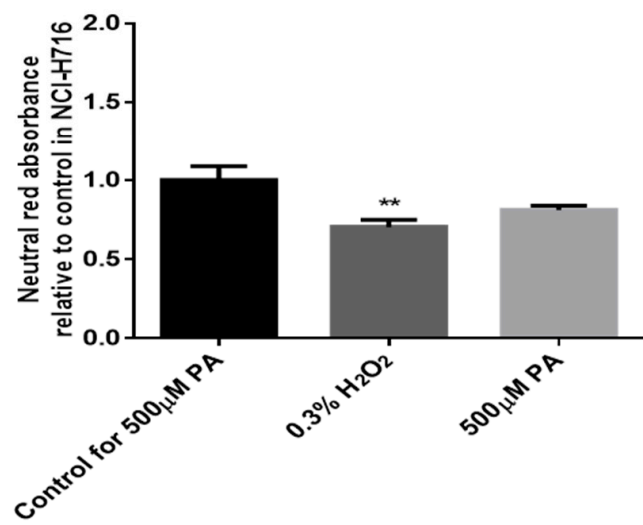

d

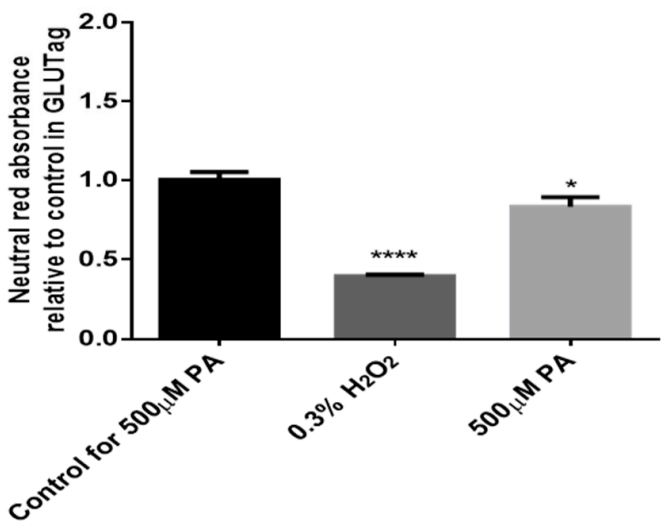

Figure 1. Palmitate-induced reactive oxygen species (ROS) production in NCI-H716 and GLUTag cells. ROS generation $(\mathbf{a}, \mathbf{b})$ was determined after a 2-h incubation with $2^{\prime}, 7^{\prime}$-DCF-DA and palmitate treatment and regular bovine serum albumin (BSA) as control. Cell viability (c,d) was assessed via neutral red absorbance after a 2-h incubation with neutral red dye and indicated treatments. Data were analyzed using a Two-way ANOVA followed by Bonferroni post hoc test, ${ }^{*}=p<0.1,{ }^{* *}=p<0.01$, ${ }^{* * *}=p<0.001,^{* * *}=p<0.0001$. Results are expressed as means $\pm \mathrm{SEM}, \mathrm{n}=8$.

\subsection{GYY4137, a Slow-Releasing $\mathrm{H}_{2} \mathrm{~S}$ Donor, Reduces Basal and Palmitate-Induced ROS in NCI-H716 Cells}

To investigate the direct effect of $\mathrm{H}_{2} \mathrm{~S}$ on ROS, NCI-H716 cells were treated with a slow-releasing $\mathrm{H}_{2} \mathrm{~S}$ donor, GYY4137. GYY4137 at $1 \mathrm{mM}$ significantly reduced basal ROS by half after $120 \mathrm{~min}$ of treatment $(0.593 \pm 0.022$-fold of control, $p<0.0001$, Figure $2 \mathrm{~A}) .500 \mu \mathrm{M}$ PA-induced ROS was significantly reduced by $25 \%$ by co-incubating cells with $1 \mathrm{mM}$ of GYY4137 $(1.219 \pm 0.036$-fold with GYY4137 versus $1.478 \pm 0.036$-fold without GYY4137, $p<0.0001$, Figure 2B).

A

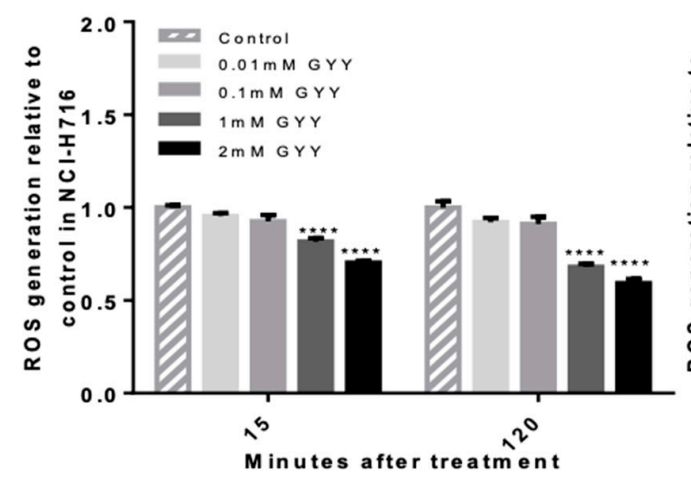

B

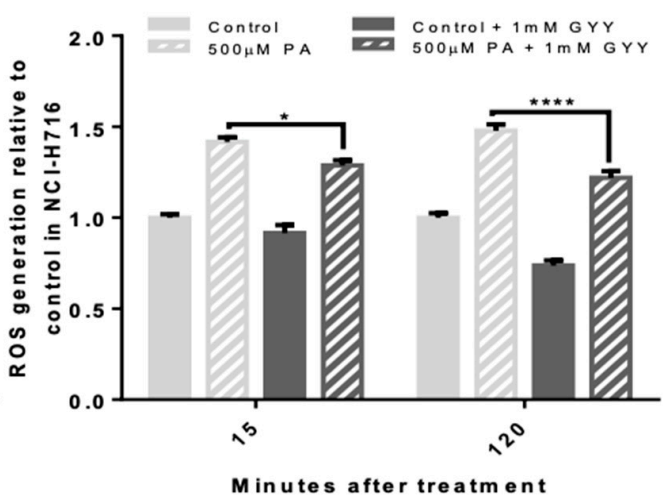

Figure 2. The antioxidant effect of $\mathrm{H}_{2} \mathrm{~S}$ donor on basal and palmitate-induced ROS in NCI-H716 cells. Fluorescence was analyzed after a 2-h incubation with $2^{\prime}, 7^{\prime}$-DCF-DA and treatments. (A) $1 \mathrm{mM}$ and $2 \mathrm{mM}$ of GYY4137 significantly reduces basal ROS by nearly half. (B) $500 \mu \mathrm{M}$ PA-induced ROS was significantly reduced by co-incubating cells with GYY4137 at $1 \mathrm{mM}$. Data were analyzed using a Two-way ANOVA followed by Bonferroni post hoc test, ${ }^{*}=p<0.01,{ }^{* * * *}=p<0.0001$ ). Results are expressed as means \pm SEM $n=8$.

3.3. Western Diet Elevates Body Weight in Both Sexes and Elevates Fasting Blood Glucose and Lipid Peroxidation in Male Mice

To investigate the effect of elevated PA in vivo, mice were fed either a chow diet or a Western diet rich in PA. Western diet elevated body weight in both sexes with a pronounced weight difference in 
males at 16 weeks $(43.445 \pm 0.761 \mathrm{~g}$ for WD-fed mice compared to $33.050 \pm 1.485 \mathrm{~g}$ for chow diet-fed mice, $p<0.0001$, Figure 3B) that appeared much earlier than in the females $(31.145 \pm 1.896 \mathrm{~g}$ for WD-fed mice versus $23.950 \pm 0.866$ for chow diet-fed mice, $p<0.0001$, Figure 3A). No significant elevation in fasting blood glucose was seen in females at 16 weeks $(7.775 \pm 0.795 \mathrm{mM}$ for WD-fed mice versus $6.475 \pm 0.226 \mathrm{mM}$ for chow diet-fed mice, Figure 3C) while a much greater elevation was seen in males $(10.550 \pm 0.572 \mathrm{mM}$ for WD-fed mice versus $7.900 \pm 0.593 \mathrm{mM}$ for chow diet-fed mice, $p<0.0001$, Figure 3D). Circulating lipid peroxidation was assessed by MDA assay and levels were only elevated in the WD-fed males $(184.515 \pm 2.011 \mathrm{nmol} / \mathrm{mL}$ for WD-fed mice versus $112.660 \pm 1.845 \mathrm{nmol} / \mathrm{mL}$ for chow diet-fed mice, $p<0.0001$, Figure $3 \mathrm{E}$ ).
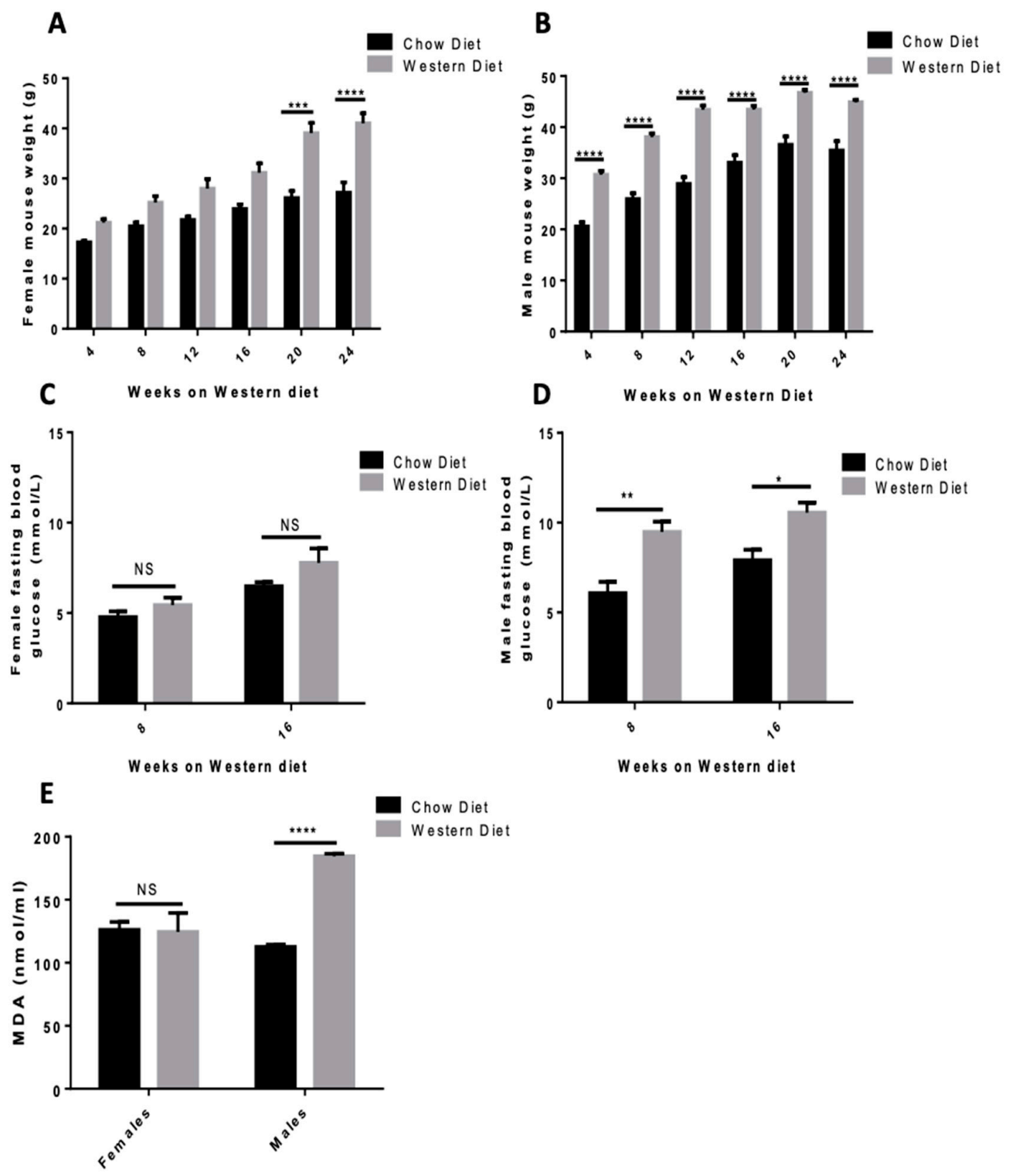

Weeks on Western diet

Figure 3. Western diet effect on mice body weight, fasting blood glucose, and lipid peroxidation. Body weight was examined in female (A) and male (B) mice maintained for 24 weeks on a Western or chow diet. Fasting blood glucose at 8 and 16 weeks was examined in female (C) and male mice (D) on a Western and chow diet. (E) Circulating lipid peroxidation was examined in both sexes after 24 weeks on a Western or chow diet. Data were analyzed using a Two-way ANOVA followed by Bonferroni post hoc test, ${ }^{*}=p<0.1,{ }^{* *}=p<0.01,^{* * *}=p<0.001,{ }^{* * * *}=p<0.0001$ ). Results are expressed as means \pm SEM $n=11$ Western diet, $\mathrm{n}=4$ chow diet. 


\subsection{The $\mathrm{H}_{2} \mathrm{~S}$ Donor, GYY4137, Improves Oral Glucose Tolerance in Western Diet-Fed Male Mice}

Blood glucose response after an oral glucose challenge $(2 \mathrm{~g} / \mathrm{kg})$ was examined in fasted mice given an IP injection of GYY4137 (30 mg/kg) or saline at $-16 \mathrm{~h}$. No significant change was observed in females injected with $\mathrm{H}_{2} \mathrm{~S}$ compared to control (Figure $4 \mathrm{~A}, \mathrm{~B}$ ). Glucose tolerance was significantly improved in males injected with the $\mathrm{H}_{2} \mathrm{~S}$ donor $(p<0.01$ for treatment effect, Figure $4 \mathrm{C}, \mathrm{D})$.

A

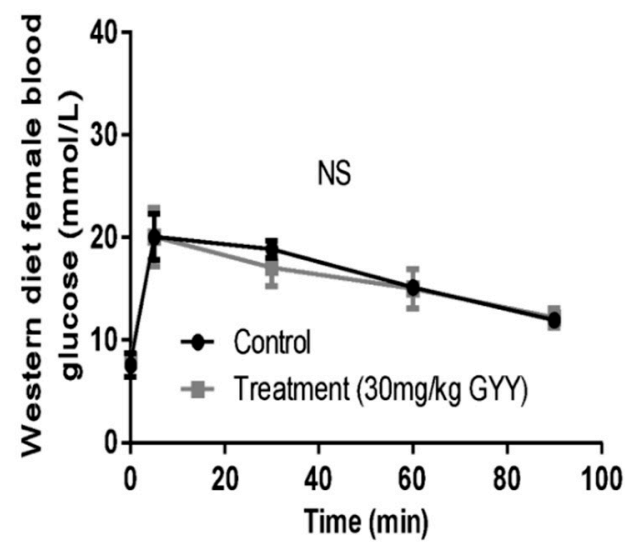

C

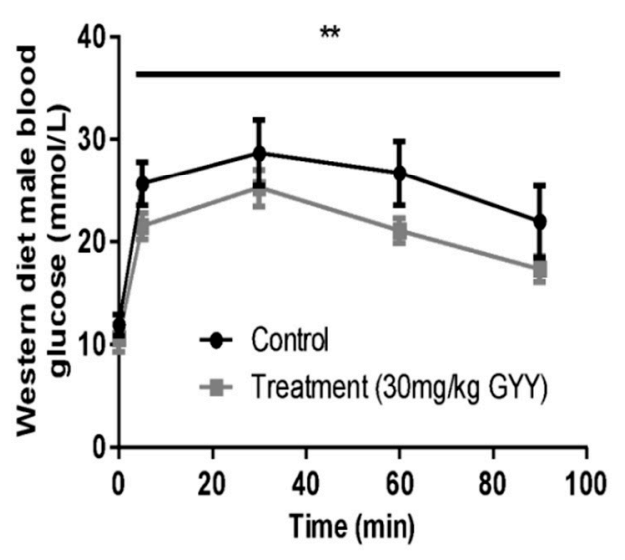

B
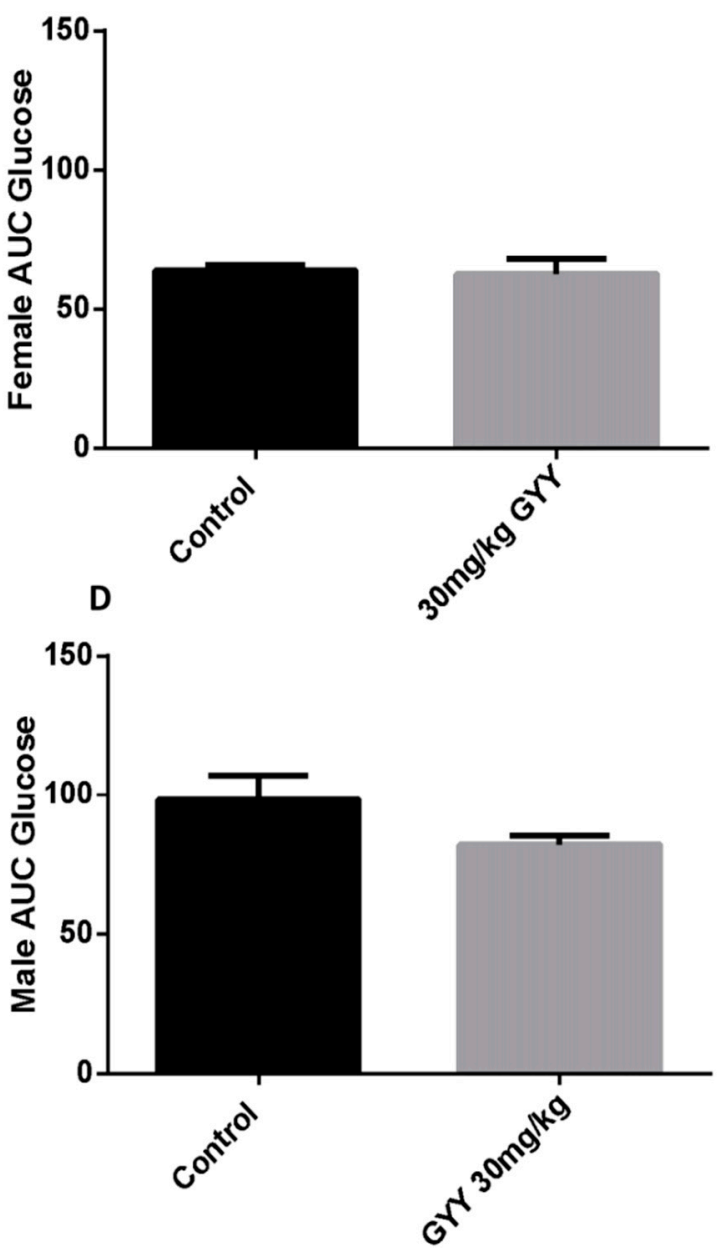

Figure 4. The glucoregulatory effect of $\mathrm{H}_{2} \mathrm{~S}$ donor in Western diet-fed mice. Plasma glucose levels in response to an oral glucose challenge was examined in fasted mice given an intraperitoneal (IP) injection of GYY4137 $(30 \mathrm{mg} / \mathrm{kg}$ ) or saline at $-16 \mathrm{~h}$. Glucose concentration and area under the curve (AUC) were assessed in female $(\mathbf{A}, \mathbf{B})$ and male $(\mathbf{C}, \mathbf{D})$ mice. Results are expressed as absolute glucose means \pm SEM over time after oral glucose challenge $(2 \mathrm{~g} / \mathrm{kg})$. Data were analyzed using a Two-way ANOVA, ${ }^{* *}=p<0.05$ effect for the treatment. $\mathrm{N}=6$ treatments and $\mathrm{n}=5$ controls.

\subsection{The $\mathrm{H}_{2} \mathrm{~S}$ Donor, GYY4137, Enhances Glucose Stimulated GLP-1 Release in Western Diet-Fed Mice}

Plasma GLP-1 response to an oral glucose challenge was examined in WD-fed mice given an intraperitoneal (IP) injection of GYY4137 (30 mg/kg) or saline at $-16 \mathrm{~h}$. Animals (combined male and female) receiving GYY4137 had a greater elevation (delta) in 5 min GLP-1 release $(12.774 \pm 4.402$ for GYY4137-treated mice compared to $2.041 \pm 3.205$ for control, $p<0.05$, Figure 5A). Absolute GLP-1 at time 0 (basal) was similar in between groups (25.7 pM in control vs. 27.3 pM in GYY4137). The enhancement in GLP-1 was more pronounced in male mice as WD-fed males had completely lost their GLP-1 response (peak of $16.728 \pm 7.015$ for GYY4137-treated mice compared to $-0.626 \pm 5.991$ for 
control, $p<0.05$, Figure 5C). Males had a similar basal GLP-1 concentration of $28.4 \mathrm{pM}$ in control and $30.3 \mathrm{pM}$ in GYY4137. In females, a much smaller improvement was observed (peak at $6.843 \pm 1.673$ for GYY4137-treated mice compared to $4.709 \pm 2.602$ for control, Figure 5B). Basal GLP-1 levels were also similar in females with $24.1 \mathrm{pM}$ in control and $25.8 \mathrm{pM}$ in GYY4137 treated.

A

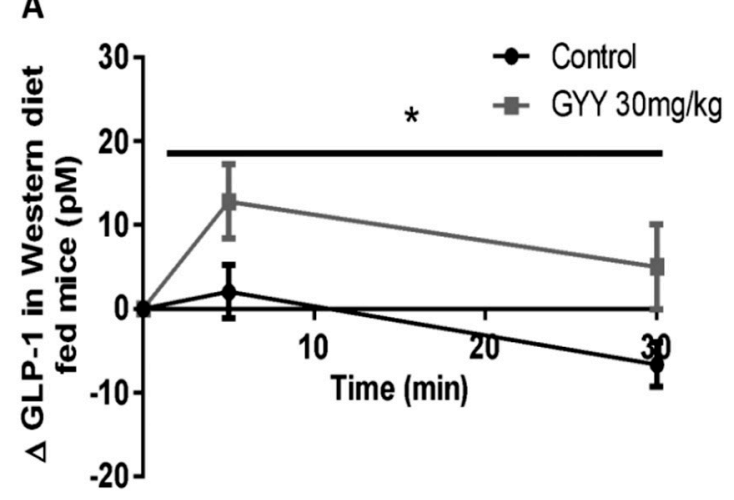

C

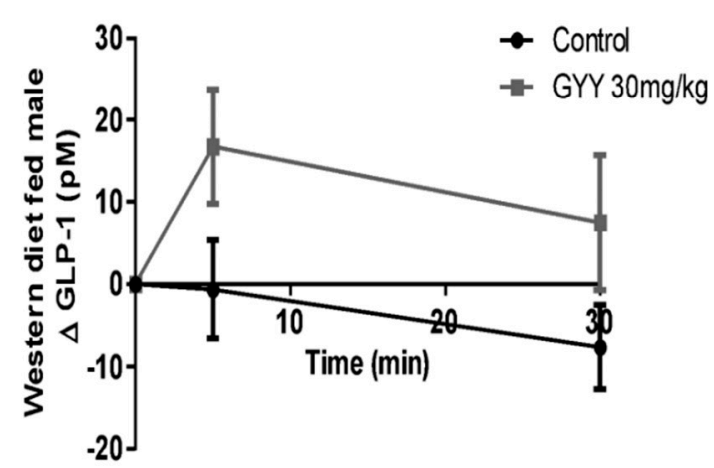

B

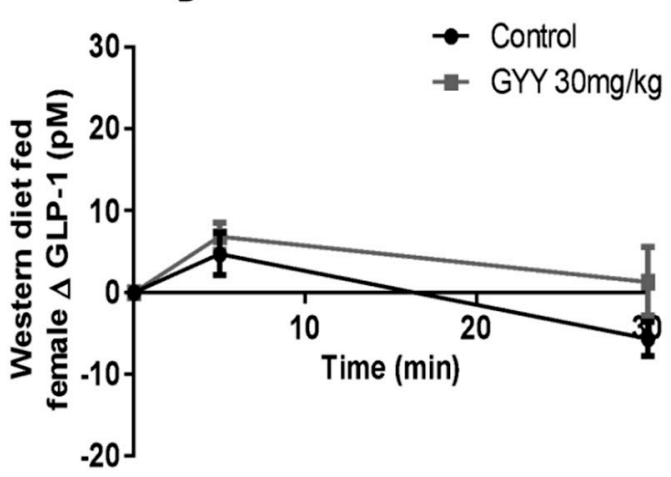

Figure 5. The effect of $\mathrm{H}_{2} \mathrm{~S}$ donor on glucose-stimulated GLP-1 release in Western diet-fed mice. Plasma GLP-1 response to an oral glucose challenge was examined in fasted mice given an IP injection of GYY4137 (30 mg/kg) or saline at $-16 \mathrm{~h}$. GLP-1 response was assessed as combined male and female (A), female (B), and male mice (C). Results are expressed as the change in GLP-1 from baseline in means \pm SEM over time after oral glucose challenge $(2 \mathrm{~g} / \mathrm{kg})$. Data were analyzed using a Two-way ANOVA, ${ }^{*}=p<0.05$ effect for the treatment. $\mathrm{n}=12$ treatments and $\mathrm{n}=10$ controls in $(\mathbf{A})$ and $\mathrm{n}=6$ treatments and $n=5$ controls in $(\mathbf{B}, \mathbf{C})$.

\section{Discussion}

Obesity is associated with elevated circulating free fatty acids including PA, a highly abundant saturated fatty acid found in high-fat diets [21]. The excessive dietary amounts of PA have been implicated in metabolic stress resulting from oxidative stress elevation by constant ROS production [13]. Oxidative stress causes cytotoxicity that eventually results in cell dysfunction, leading to apoptosis when those cells show a low antioxidant defense and cannot counteract the excess amount of ROS production [11]. Therefore, PA-induced oxidative stress may explain GLP-1 secretion impairment during obesity. While current studies recognize the cytotoxicity that may arise from elevated levels of PA in vitro in chronic conditions [22,23], they do not determine to what extent this cytotoxicity impairs L-cells, and whether this oxidative stress can be reversed.

To explore the effects of acute PA treatment in physiological and pathophysiological simulations, three doses of PA-125 $\mu \mathrm{M}, 250 \mu \mathrm{M}$, and $500 \mu \mathrm{M}$ —-were used. To mimic circulating plasma PA during obesity, lipotoxic conditions can be simulated by incubating cells with $500 \mu \mathrm{M}$ of palmitate [23]. Indeed, 
we found the $500 \mu \mathrm{M}$ PA caused the most significant production of ROS by over threefold in NCI-H716 cells and twofold in GLUTag cells. This is in agreement with previous work in GLUTag's demonstrating PA-induced ER stress [23]. Interestingly, in our work the NCI-H716 cells required the $500 \mu \mathrm{M}$ dose of PA to induce ROS, whereas the GLUTag's had significant induction of ROS at all the tested doses. We also note, that the degree of ROS induction in the NCI-H716 cells was nearly double that of the GLUTag cells. Although NCI-H716 and GLUTag cell lines are both enteroendocrine L-cell models, they vary considerably from one another, and this may explain the differences seen in dose-dependent ROS generation [24]. One possible explanation is that the levels of endogenous antioxidants may vary between the two cell lines. There may be higher levels of antioxidants present in the NCI-H716 cells, which can counteract the lower does PA-induced levels of ROS. Indeed, when the cells were examined for PA-induced cytotoxicity using the neutral red test, a significant reduction in viability was observed in GLUTag and not NCI-H716 cells. Additional experiments exploring the antioxidant capacity of each of these cell models may resolve this discrepancy. It is important to recognize that in vivo, a variety of fatty acids and cell stress inducers would be present and that an animal model of high fat diet-induced oxidative stress will better recapitulate the fatty acid environment of L-cells.

While we did not explore the precise mechanism of palmitate's ROS inducing effects in L-cells, this saturated fatty acid is a well-established inducer of ER stress, Superoxide anion generation, and altered cellular calcium regulation, reviewed in [13]. Recently, palmitate's ability to impair GLP-1 secretion in L-cells (induced by insulin) has been described [23]. In this work, L-cells exposed to palmitate had altered processing of the GLP-1 precursor, proglucagon, which led to glucagon production rather than GLP-1. The reduced GLP-1 and enhanced glucagon production, are likely major contributors to the lipotoxicity-induced impaired glucose regulation. This known lipotoxic effect led us to explore a protective mechanism.

In the cell experiments, we demonstrated the antioxidant capacity of the $\mathrm{H}_{2} \mathrm{~S}$ donor GYY4137. On its own, and in PA-induced ROS generation, $\mathrm{H}_{2} \mathrm{~S}$ was able to reduce ROS levels. $\mathrm{H}_{2} \mathrm{~S}$ is well established as an antioxidant gas. Hydrogen sulfide exhibits antioxidant proprieties in two ways. First, $\mathrm{H}_{2} \mathrm{~S}$ has a weak reducing propriety, which can react chemically with the superoxide anion [25]. Second, $\mathrm{H}_{2} \mathrm{~S}$ can upregulate antioxidant enzymes such as glutathione peroxidase [26,27] and superoxide dismutase [28] through its S-sulfhydration action [29,30]. Future in-depth cell studies will elucidate the mechanism being employed in L-cells.

Next, we explored the effects of the PA-rich Western diet (WD) oxidative stress, GLP-1 regulation, and glucose regulation in C57BL/6 mice. As expected, WD elevated body weight in both female and male mice [31]. However, males had a greater increase in body weight at an earlier point in the study and exhibited a greater elevation in fasting blood glucose relative to females. Importantly these indications of metabolic dysfunction aligned with the degree of circulating peroxidated lipids found in males (measured as MDA levels). While MDA does not provide a clear sense of the oxidative stress within the L-cells, it does serve as a proxy for the degree of oxidative stress in the animal [32]. It is possible the females were less sensitive to WD-induced metabolic dysfunction due to the elevated levels of estrogen. Estrogen is known to induce lipid oxidation for use as an energy source [33] and also plays a beneficial role in glucose homeostasis, as low estrogens can lead to insulin resistance [34]. Since our experimental design included both male and female mice, we were able to detect this difference in WD sensitivity.

We then tested the effect of a single injection of the $\mathrm{H}_{2} \mathrm{~S}$ donor GYY4137 in WD-fed mice. While we were not equipped to measure the precise blood concentration of $\mathrm{H}_{2} \mathrm{~S}$ before and $16 \mathrm{~h}$ after GYY4137 delivery, we selected GYY4137 over sulfide salts as concentrations remain 3 days once in solution [35]. With a $30 \mu \mathrm{g} / \mathrm{g}$ GYY4137 IP dose, and based on a mouse blood volume estimates, $\mathrm{H}_{2} \mathrm{~S}$ levels in the blood were likely in the $\mu \mathrm{M}$ range. Future spectroscopic measurement of $\mathrm{H}_{2} \mathrm{~S}$ and sulfur derivatives including persulfides and polysulfides in blood will further clarify this.

GYY4137 caused a significant improvement in glucose tolerance and GLP-1 secretion relative to control. It's important to note that female mice, despite being on the WD for 16 weeks, did not exhibit 
the same degree of impaired glucose tolerance or impaired GLP-1 secretion compared to males. Indeed, the GLP-1 response to oral glucose was completely lost in WD-fed male mice. It should be noted, that despite the significant overall effect of GYY4137 on GLP-1 response in male and female combined data, neither sex separately reached statistical significance. To determine whether $\mathrm{H}_{2} \mathrm{~S}$ has the ability to rescue WD-induced metabolic impairment in females, future studies may require a longer diet duration relative to the one used in males. It should be noted that our route of administration for the $\mathrm{H}_{2} \mathrm{~S}$ donor was IP. When injecting the compound, $\mathrm{H}_{2} \mathrm{~S}$ will diffuse throughout the body [26] including the intestinal villi [36] where L-cells are located. Indeed, IP injections of GYY4137 have been previously shown to impact villus structure [36] suggesting the compounds ability to reach the intestine.

The enhanced GLP-1 secretion in mice receiving GYY4137 is in line with our labs' previous work in both L-cells and in mice [16]. In that study, GYY4137 enhanced GLP-1 secretion by nearly twofold compared with vehicle-treated GLUTag cells. In mice, $\mathrm{H}_{2} \mathrm{~S}$ levels were increased by administering a probiotic diet that enhanced sulfate-reducing bacteria. While this previous work provided a novel mechanism using the gut microbiome to enhance $\mathrm{H}_{2} \mathrm{~S}$ and GLP-1, the current study demonstrated a role for $\mathrm{H}_{2} \mathrm{~S}$ to protect from fatty acid-induced metabolic stress. Indeed, the potential role of $\mathrm{H}_{2} \mathrm{~S}$ as a therapeutic treatment is promising as trials are underway exploring its anti-inflammatory properties [37].

\section{Conclusions}

In conclusion, our work demonstrates that $\mathrm{H}_{2} \mathrm{~S}$ not only reduces oxidative stress induced by PA in L-cells but also enhances GLP-1 secretion and improves glucose clearance in mice. This study will lay the foundation for future work exploring $\mathrm{H}_{2} \mathrm{~S}$ as a potential therapeutic agent in the treatment of complications associated with obesity.

Author Contributions: Conceptualization, A.M. and J.G.; methodology, A.M. and R.N.; validation, J.G.; formal analysis, A.M.; investigation, A.M.; resources, J.G.; data curation, A.M. and R.N.; writing-original draft preparation, A.M.; writing-review and editing, A.M., J.G., R.N.; visualization, A.M.; supervision, J.G; funding acquisition, J.G. All authors have read and agreed to the published version of the manuscript.

Funding: The authors are greatly thankful for financial support to by Natural Sciences and Engineering Research Council Discovery Grant RGPIN-2016-05905.

Conflicts of Interest: The authors declare no conflict of interest.

\section{References}

1. Marseglia, L.; Manti, S.; D’Angelo, G.; Nicotera, A.; Parisi, E.; Di Rosa, G.; Gitto, E.; Arrigo, T. Oxidative stress in obesity: A critical component in human diseases. Int. J. Mol. Sci. 2014, 16, 378-400. [CrossRef] [PubMed]

2. Lebovitz, H.E.; Banerji, M.A. Point: Visceral Adiposity Is Causally Related to Insulin Resistance. Diabetes Care 2005, 28, 2322-2325. [CrossRef] [PubMed]

3. Paccosi, S.; Cresci, B.; Pala, L.; Rotella, C.M.; Parenti, A. Obesity Therapy: How and Why? Curr. Med. Chem. 2020, 27, 174-186. [CrossRef]

4. Brunton, S. GLP-1 Receptor Agonists vs. DPP-4 Inhibitors for Type 2 Diabetes: Is One Approach More Successful or Preferable than the Other? Int. J. Clin. Pract. 2014, 68, 557-567. [CrossRef] [PubMed]

5. Gallwitz, B. Clinical Use of DPP-4 Inhibitors. Front. Endocrinol. (Lausanne) 2019, 10. [CrossRef] [PubMed]

6. Heppner, K.M.; Perez-Tilve, D. GLP-1 Based Therapeutics: Simultaneously Combating T2DM and Obesity. Front. Neurosci. 2015, 9. [CrossRef] [PubMed]

7. Hira, T.; Pinyo, J.; Hara, H. What Is GLP-1 Really Doing in Obesity? Trends Endocrinol. Metab. 2020, 31, 71-80. [CrossRef]

8. Drucker, D.J.; Nauck, M.A. The Incretin System: Glucagon-like Peptide-1 Receptor Agonists and Dipeptidyl Peptidase-4 Inhibitors in Type 2 Diabetes. Lancet 2006, 368, 1696-1705. [CrossRef]

9. Madsbad, S. The Role of Glucagon-like Peptide-1 Impairment in Obesity and Potential Therapeutic Implications. Diabetes Obes. Metab. 2014, 16, 9-21. [CrossRef] 
10. Furukawa, S.; Fujita, T.; Shimabukuro, M.; Iwaki, M.; Yamada, Y.; Nakajima, Y.; Nakayama, O.; Makishima, M.; Matsuda, M.; Shimomura, I. Increased Oxidative Stress in Obesity and Its Impact on Metabolic Syndrome. J. Clin. Investig. 2004, 114, 1752-1761. [CrossRef]

11. Asmat, U.; Abad, K.; Ismail, K. Diabetes Mellitus and Oxidative Stress-A Concise Review. Saudi Pharm. J. 2016, 24, 547-553. [CrossRef] [PubMed]

12. Gerber, P.A.; Rutter, G.A. The Role of Oxidative Stress and Hypoxia in Pancreatic Beta-Cell Dysfunction in Diabetes Mellitus. Antioxid. Redox Signal. 2017, 26, 501-518. [CrossRef] [PubMed]

13. Ly, L.D.; Xu, S.; Choi, S.-K.; Ha, C.-M.; Thoudam, T.; Cha, S.-K.; Wiederkehr, A.; Wollheim, C.B.; Lee, I.-K.; Park, K.-S. Oxidative Stress and Calcium Dysregulation by Palmitate in Type 2 Diabetes. Exp. Mol. Med. 2017, 49, e291. [CrossRef] [PubMed]

14. Shefa, U.; Kim, M.-S.; Jeong, N.Y.; Jung, J. Antioxidant and Cell-Signaling Functions of Hydrogen Sulfide in the Central Nervous System. Oxidative Med. Cell. Longev. 2018. [CrossRef] [PubMed]

15. Chiku, T.; Padovani, D.; Zhu, W.; Singh, S.; Vitvitsky, V.; Banerjee, R. H2S Biogenesis by Human Cystathionine $\gamma$-Lyase Leads to the Novel Sulfur Metabolites Lanthionine and Homolanthionine and Is Responsive to the Grade of Hyperhomocysteinemia. J. Biol. Chem. 2009, 284, 11601-11612. [CrossRef]

16. Singh, S.B.; Lin, H.C. Hydrogen Sulfide in Physiology and Diseases of the Digestive Tract. Microorganisms 2015, 3, 866-889. [CrossRef]

17. Pichette, J.; Fynn-Sackey, N.; Gagnon, J. Hydrogen Sulfide and Sulfate Prebiotic Stimulates the Secretion of GLP-1 and Improves Glycemia in Male Mice. Endocrinology 2017, 158, 3416-3425. [CrossRef]

18. Hughes, C.S.; Postovit, L.M.; Lajoie, G.A. Matrigel: A Complex Protein Mixture Required for Optimal Growth of Cell Culture. Proteomics 2010, 10, 1886-1890. [CrossRef]

19. Cousin, S.P.; Hügl, S.R.; Wrede, C.E.; Kajio, H.; Myers, M.G., Jr.; Rhodes, C.J. Free fatty acid induced inhibition of glucose and insulin-like growth factor I-induced deoxyribonucleic acid synthesis in the pancreatic $\beta$-cell line INS-1. Endocrinology 2001, 142, 229-240. [CrossRef]

20. Repetto, G.; del Peso, A.; Zurita, J.L. Neutral Red Uptake Assay for the Estimation of Cell Viability/Cytotoxicity. Nat. Protoc. 2008, 3, 1125-1131. [CrossRef]

21. Arner, P.; Rydén, M. Fatty Acids, Obesity and Insulin Resistance. Obes. Facts 2015, 8, 147-155. [CrossRef]

22. Vasu, S.; Moffett, R.C.; McClenaghan, N.H.; Flatt, P.R. Differential Molecular and Cellular Responses of GLP-1 Secreting L-Cells and Pancreatic Alpha Cells to Glucotoxicity and Lipotoxicity. Exp. Cell Res. 2015, 336, 100-108. [CrossRef] [PubMed]

23. Filippello, A.; Urbano, F.; Di Mauro, S.; Scamporrino, A.; Di Pino, A.; Scicali, R.; Rabuazzo, A.M.; Purrello, F.; Piro, S. Chronic Exposure to Palmitate Impairs Insulin Signaling in an Intestinal L-Cell Line: A Possible Shift from GLP-1 to Glucagon Production. Int. J. Mol. Sci. 2018, 19. [CrossRef]

24. Kuhre, R.E.; Wewer Albrechtsen, N.J.; Deacon, C.F.; Balk-Møller, E.; Rehfeld, J.F.; Reimann, F.; Gribble, F.M.; Holst, J.J. Peptide Production and Secretion in GLUTag, NCI-H716, and STC-1 Cells: A Comparison to Native L-Cells. J. Mol. Endocrinol. 2016, 56, 201-211. [CrossRef]

25. Al-Magableh, M.R.; Kemp-Harper, B.K.; Hart, J.L. Hydrogen Sulfide Treatment Reduces Blood Pressure and Oxidative Stress in Angiotensin II-Induced Hypertensive Mice. Hypertens. Res. 2015, 38, 13-20. [CrossRef]

26. Cheung, S.H.; Lau, J.Y.W. Hydrogen Sulfide Mediates Athero-Protection against Oxidative Stress via S-Sulfhydration. PLoS ONE 2018, 13, e0194176. [CrossRef]

27. Bian, J.-S.; Olson, K.R.; Zhu, Y.-C. Hydrogen Sulfide: Biogenesis, Physiology, and Pathology. Oxidative Med. Cell. Longev. 2016, 2016, 6549625. [CrossRef]

28. Sun, W.-H.; Liu, F.; Chen, Y.; Zhu, Y.-C. Hydrogen Sulfide Decreases the Levels of ROS by Inhibiting Mitochondrial Complex IV and Increasing SOD Activities in Cardiomyocytes under Ischemia/Reperfusion. Biochem. Biophys. Res. Commun. 2012, 421, 164-169. [CrossRef]

29. Mustafa, A.K.; Gadalla, M.M.; Sen, N.; Kim, S.; Mu, W.; Gazi, S.K.; Barrow, R.K.; Yang, G.; Wang, R.; Snyder, S.H. H2S Signals through Protein S-Sulfhydration. Sci. Signal. 2009, 2, ra72. [CrossRef]

30. Filipovic, M.R.; Zivanovic, J.; Alvarez, B.; Banerjee, R. Chemical Biology of H2S Signaling through Persulfidation. Chem. Rev. 2018, 118, 1253-1337. [CrossRef]

31. Baena, M.; Sangüesa, G.; Hutter, N.; Beltrán, J.M.; Sánchez, R.M.; Roglans, N.; Alegret, M.; Laguna, J.C. Liquid Fructose in Western-Diet-Fed Mice Impairs Liver Insulin Signaling and Causes Cholesterol and Triglyceride Loading without Changing Calorie Intake and Body Weight. J. Nutr. Biochem. 2017, 40, 105-115. [CrossRef] [PubMed] 
32. Yonny, M.E.; García, E.M.; López, A.; Arroquy, J.I.; Nazareno, M.A. Measurement of Malondialdehyde as Oxidative Stress Biomarker in Goat Plasma by HPLC-DAD. Microchem. J. 2016, 129, 281-285. [CrossRef]

33. Mauvais-Jarvis, F.; Clegg, D.J.; Hevener, A.L. The Role of Estrogens in Control of Energy Balance and Glucose Homeostasis. Endocr. Rev. 2013, 34, 309-338. [CrossRef] [PubMed]

34. Mauvais-Jarvis, F. Sex Differences in Metabolic Homeostasis, Diabetes, and Obesity. Biol. Sex Differ. 2015, 6, 14. [CrossRef]

35. Lee, Z.W.; Zhou, J.; Chen, C.-S.; Zhao, Y.; Tan, C.-H.; Li, L.; Moore, P.K.; Deng, L.-W. The Slow-Releasing Hydrogen Sulfide Donor, GYY4137, Exhibits Novel Anti-Cancer Effects In Vitro and In Vivo. PLoS ONE 2011, 6. [CrossRef]

36. Drucker, N.A.; Jensen, A.R.; Te Winkel, J.P.; Markel, T.A. Hydrogen Sulfide Donor GYY4137 Acts through Endothelial Nitric Oxide to Protect Intestine in Murine Models of Necrotizing Enterocolitis and Intestinal Ischemia. J. Surg Res. 2019, 234, 294-302. [CrossRef]

37. Magierowski, M.; Magierowska, K.; Surmiak, M.; Hubalewska-Mazgaj, M.; Kwiecien, S.; Wallace, J.L.; Brzozowski, T. The Effect of Hydrogen Sulfide-Releasing Naproxen (ATB-346) versus Naproxen on Formation of Stress-Induced Gastric Lesions, the Regulation of Systemic Inflammation, Hypoxia and Alterations in Gastric Microcirculation. J. Physiol. Pharmacol. 2017, 68, 749-756.

Publisher's Note: MDPI stays neutral with regard to jurisdictional claims in published maps and institutional affiliations.

(C) 2020 by the authors. Licensee MDPI, Basel, Switzerland. This article is an open access article distributed under the terms and conditions of the Creative Commons Attribution (CC BY) license (http://creativecommons.org/licenses/by/4.0/). 